\title{
Real-Time Pricing Strategy Based on the Stability of Smart Grid for Green Internet of Things
}

\author{
Huwei Chen, ${ }^{1}$ Hui Hui, ${ }^{1}$ Zhou Su, $^{1}$ Dongfeng Fang, ${ }^{2}$ and Yilong Hui ${ }^{1}$ \\ ${ }^{1}$ School of Mechatronic Engineering and Automation, Shanghai University, Shanghai 200072, China \\ ${ }^{2}$ Department of Electrical and Computer Engineering, University of Nebraska-Lincoln (UNL), Lincoln, NE, USA \\ Correspondence should be addressed to Zhou Su; zhousu@ieee.org
}

Received 16 December 2016; Accepted 23 February 2017; Published 20 March 2017

Academic Editor: Ning Zhang

Copyright (c) 2017 Huwei Chen et al. This is an open access article distributed under the Creative Commons Attribution License, which permits unrestricted use, distribution, and reproduction in any medium, provided the original work is properly cited.

\begin{abstract}
The ever increasing demand of energy efficiency and the strong awareness of environment have led to the enhanced interests in green Internet of things (IoTs). How to efficiently deliver power, especially, with the smart grid based on the stability of network becomes a challenge for green IoTs. Therefore, in this paper we present a novel real-time pricing strategy based on the network stability in the green IoTs enabled smart grid. Firstly, the outage is analyzed by considering the imbalance of power supply and demand as well as the load uncertainty. Secondly, the problem of power supply with multiple-retailers is formulated as a Stackelberg game, where the optimal price can be obtained with the maximal profit for retailers and users. Thirdly, the stability of price is analyzed under the constraints. In addition, simulation results show the efficiency of the proposed strategy.
\end{abstract}

\section{Introduction}

Internet of things (IoTs) has emerged as a new paradigm for the next generation to enable diverse objects to exchange and collect data with each other. Compared with the conventional paradigms, more considerations are given to develop the green IoTs where new energy efficient devices, protocols, and architectures have been designed to interconnect with the physical world [1-4]. Among the enabling green IoTs technologies, the smart grid $[5,6]$ plays an important role in realizing the green IoTs [7-10].

In the smart grid, the power can be delivered with the two-way flow of information. The smart grid can form heterogeneous networks to connect the power supplier and consumers with various devices [11-15]. The green network technologies have been widely applied to manage, control, and optimize the smart grid in the green IoTs [16-20].

For example, smart meters have been deployed in smart grid to obtain the two-way flow of information and monitor the power supply. Besides, heterogeneous networks with small cells can support the spectrum sensing in smart grid [21]. It makes it possible that the secondary users can utilize the unoccupied channel when the primary users are absent, resulting in an efficient use of the resources of spectrum in smart grid [22-24].

However, it also brings new challenges as follows. (1) As the delivery of power and data may be interrupted due to the outage, the delivery of energy based on the stability of networks needs to be discussed. (2) To improve the quality of experience (QoE) for users in green IoTs, the suitable pricing approach should be studied by considering both the demand of users and the generation of power in green IoTs.

Although there have been some existing approaches [2530], they could not efficiently resolve the problems with the following reasons. On one hand, most of them focus on demand-side management in smart grid, where the stability of networks is not considered enough. On the other hand, the effect of outage in networks is not studied with the result that network resources are not efficiently used.

In this paper, in order to resolve the above problems, we propose the real-time pricing strategy based on the stability of smart grid for green IoTs. At first, we analyze the outage which is related to the imbalance of power supply and demand as well as load uncertainty. The power supply model is also developed with the transmission constraints. Then, we formulate the problem of power supply for multiple-retailers 
as a Stackelberg dynamic game. The optimal price can be obtained with the maximal profit for retailers while the price is stable under the load constraints. Simulation results show the effectiveness of the proposed strategy.

Unlike aforementioned works, we study how to obtain the optimal price strategy based on the system stability in the heterogeneous network. The main contributions of our paper are summarized as follows.

(i) Based on the direct and cooperative communication, respectively, the new power demand model for users is formulated. The load uncertainty resulted from the outage in the heterogeneous networks is also analyzed.

(ii) According to the relationship between users and power retailers, we propose the novel power supply model with power transfer among different retailers. We introduce the Stackelberg game to obtain the optimal pricing strategy with maximum profits for retailers.

(iii) We further study and analyze the system stability related to the optimal decision on the pricing with the outage in the heterogeneous networks, under the constraints of the power supply and power demand.

The rest of the paper is organized as follows. Section 2 presents a brief overview of the related work. Both of the network model and power supply model are developed in Section 3. Section 4 proposes the real-time pricing strategy with multiretailers based on the Stackelberg game. The analysis of the network stability is presented in Section 5 . Section 6 discusses the performance of the proposed strategy. Section 7 concludes this paper.

\section{Related Work}

There have been a lot of related studies on the price decisionmaking and power distribution in smart grid for green IoTs. Bu et al. [27] developed a Stackelberg game model to maximize the profits for electricity suppliers with demandside management. Matamoros et al. [31] studied the energy supply in the island mode and obtained the minimum cost to deliver the power. Chiu et al. [32] built mathematical models based on the relationship between the energy generation and the energy storage devices in smart grid. Huang et al. [33] designed a robust controller with the optimal demand response to manage the storage of energy.

Singh et al. [34] analyzed the home energy management system with the real time price to improve the energy consumption. Althaher et al. [35] proposed a scheduling optimization algorithm to manage the time of household appliances according to the needs of users. Bahrami et al. [36] built an effective mathematical model to perform the schedule for household appliances to improve the electricity cost and environment protection. Feng et al. [37] presented the pricing strategy and dynamic spectrum allocation with the consideration of $\mathrm{QoE}$ and priorities of applications.

Hong and Zhu [38] studied the methods to minimize the cost of power delivery and consumption based on the power

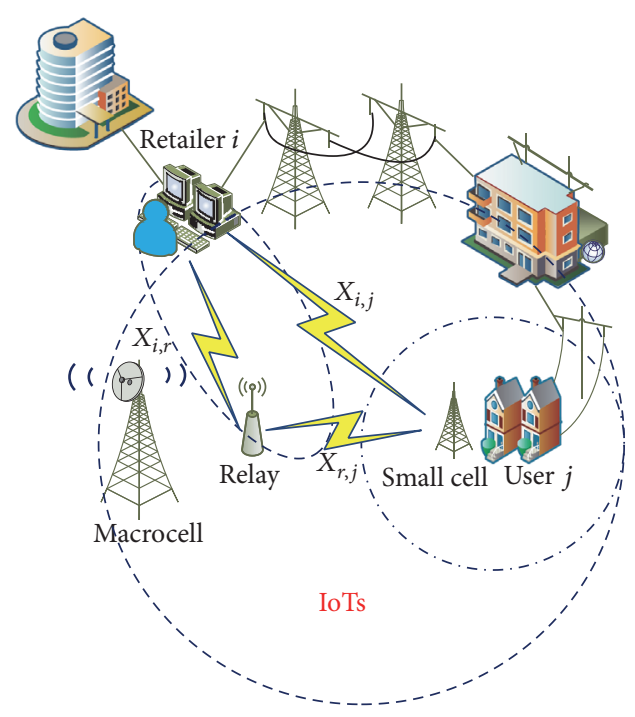

FIGURE 1: Architecture of smart grid with heterogeneous networks.

flow model. Ahmed et al. [39] discussed the relay selection mechanism for wireless cooperative communication in smart grid. Bou-Harb et al. [40] studied the cyber vulnerabilities to deal with the security threats for the smart grid. Ross et al. [41] investigated the security communication deployed in the smart grid and proposed the agent-based decentralized protection system to strengthen the security. Li and Liang [42] studied the optimal power allocation strategy with the consideration of downlink capacity by formulating it as the convex optimization problem.

Although the above existing works have made efforts to improve the real-time pricing strategy in smart grid, the optimization to improve the stability and outage is still not considered. Therefore, in this paper, we present an effective real-time pricing based on the stability of smart grid for green IoTs.

\section{System Model}

In this section, we first show the communication model. Then the power model is presented.

3.1. Communication Model. In order to read conveniently, we provide a list of major symbols in Abbreviations section, which we shall define and use in this paper. We consider a heterogeneous network consisting of small cells and macrocells which are deployed in smart grid [23]. As shown in Figure 1, retailer $i(i \in(1,2, \ldots, I))$ is located within the coverage of macrocell. These retailers can be divided into different kinds of groups based on the type of generated power, such as photovoltaic generation and wind generation. Retailer $i$ can directly communicate with users who are in the coverage of small cell. On the other hand, retailer $i$ can also make the connection with users through the relay service provided by the macrocell. Similarly, there are some users in the coverage of a small cell to buy the power and the set of users in the small cell is denoted by $\mathbf{J}=(1,2, \ldots, J)$. 
When retailer $i$ directly communicates with user $j$, the signal to noise ratio (SNR) is defined as $\gamma_{i, j}$. Then, according to [43], the probability of outage becomes

$$
\zeta_{i, j}^{\text {out }}=\operatorname{Pr}\left(\gamma_{i, j}<\gamma_{\text {th }}\right) .
$$

Here, $\gamma_{\text {th }}$ denotes the threshold of SNR.

When retailer $i$ makes the connection with user $j$ through the relay node $r$, the probability of outage is described as

$$
\begin{aligned}
\zeta_{i, r, j}^{\text {out }}=\operatorname{Pr}\left(\gamma_{i, j}<\gamma_{\text {th }}\right) \\
\quad \cdot\left[\operatorname{Pr}\left(\gamma_{i, r}<\gamma_{\text {th }}\right)+\operatorname{Pr}\left(\gamma_{i, r}>\gamma_{\text {th }}\right) \times \operatorname{Pr}\left(\gamma_{r, j}<\gamma_{\text {th }}\right)\right] .
\end{aligned}
$$

Here, $\gamma_{i, r}$ is denoted as the SNR between retailer $i$ and relay node $r$, while $\gamma_{r, j}$ is defined as the SNR between relay node $r$ and user $j$.

3.2. Power Supply Model. After buying the power from the power market or other retailers, retailers determine the price for users based on the information including the power demand, utility, and satisfaction degree of users. Smart meters are equipped to deliver information such as the power demand of users and the real-time price. Users can not only choose any one of retailers based on their interests but also adjust their power consumption to improve the power utility.

According to [27], the quadratic utility function of user $j$ $(j \in \mathbf{J})$ can be obtained by

$$
U\left(d_{j}\right)=\omega_{j} d_{j}-\frac{\xi_{j}}{2} d_{j}^{2},
$$

where $\omega_{j}$ is used to characterize user types, which is different for different users. It implies that the increase value of $\omega_{j}$ can improve user $j$ utility $U\left(d_{j}\right)$ with the same power consumption $d_{j}$ of user $j . \xi_{j}$ is the preset parameter related to the saturation point of this utility function.

Considering the power cost for power retailer $i$, the profit of user $j$ can be described by

$$
G\left(p_{i}, d_{j}\right)=U\left(d_{j}\right)-p_{i} d_{j}=\omega_{j} d_{j}-\frac{\xi_{j}}{2} d_{j}^{2}-p_{i} d_{j},
$$

where $p_{i}$ denotes the power price offered by retailer $i$.

Due to the outage during the two-way communication between user $j$ and retailer $i$, the power demand of user $j$ supplied by retailer $i$ is $\left(1-\zeta_{i}\right) d_{j}+\zeta_{i} \theta_{j}$, where $\theta_{j}$ is the load uncertainty based on outage probability $\zeta_{i}$ [37].

The probability of outage is $\zeta_{i}$ obtained by

$$
\zeta_{i}=\min \left\{\zeta_{i, r, j}^{\text {out }}, \zeta_{i, j}^{\text {out }}\right\} .
$$

Thus, (4) can be rewritten as

$$
\begin{aligned}
G\left(p_{i}, d_{j}\right)= & U\left(d_{j}\right)-p_{i} d_{j} \\
= & \omega_{j}\left[\left(1-\zeta_{i}\right) d_{j}+\zeta_{i} \theta_{j}\right] \\
& -\frac{\xi_{j}}{2}\left[\left(1-\zeta_{i}\right) d_{j}+\zeta_{i} \theta_{j}\right]^{2} \\
& -p_{i}\left[\left(1-\zeta_{i}\right) d_{j}+\zeta_{i} \theta_{j}\right] .
\end{aligned}
$$

Based on (6), as $\theta_{j}$ is a zero-mean random variable with variance $\left(\sigma_{\theta}\right)^{2}$, the expectation of user $j$ with respect to $\theta_{j}$ can be described in the following:

$$
\begin{aligned}
\mathbb{E}\left\{G\left(p_{i}, d_{j}\right)\right\}= & \omega_{j}\left(1-\zeta_{i}\right) d_{j}-\frac{\xi_{j}}{2} \zeta_{i}^{2} \sigma_{\theta}^{2} \\
& -\frac{\xi_{j}}{2}\left(1-\zeta_{i}\right)^{2} d_{j}^{2}-p_{i}\left(1-\zeta_{i}\right) d_{j} \\
= & \left(\omega_{i}-p_{i}\right)\left(1-\zeta_{i}\right) d_{j}-\frac{\xi_{y}}{2} \zeta_{i}^{2} \sigma_{\theta}^{2} \\
& -\frac{\xi_{j}}{2}\left(1-\zeta_{i}\right)^{2} d_{j}^{2} .
\end{aligned}
$$

For the amount of power demands from all users, it should not exceed the total power which can be provided by retailers. Thus, we have

$$
\sum_{j=1}^{|\mathrm{J}|}\left[\left(1-\zeta_{i}\right) d_{j}+\zeta_{i} \theta_{j}\right] \leq D_{i}
$$

where $D_{i}$ denotes the total power supply in the case that QoE between retailer $i$ and users is better.

\section{Real-Time Pricing Strategy Based Stackelberg Dynamic Model}

4.1. Power Demand of Users. Users may adjust their power consumption to obtain the maximal utility in response to the price offered by retailer $i$. The optimal consumption can be solved based on (7). As the quadratic function is a concave function, we take the first derivation with respect to $d_{j}$ to obtain the optimal consumption by

$$
\begin{aligned}
\frac{\partial \mathbb{E}\left\{G\left(p_{i}, d_{j}\right)\right\}}{\partial d_{j}} & =0 \Longrightarrow \\
\left(\omega_{j}-p_{i}\right)\left(1-\zeta_{i}\right)-\xi_{j}\left(1-\zeta_{i}\right)^{2} d_{j} & =0 \Longrightarrow \\
d_{j}^{*} & =\frac{\omega_{j}-p_{i}}{\xi_{j}\left(1-\zeta_{i}\right)} .
\end{aligned}
$$

Then, in the case that there are $J$ users supplied by retailer $i$, the real amount of the power which can be supplied to users by this retailer becomes

$$
\widehat{D}_{i}=\sum_{j \in \mathbf{J}} d_{j}^{*}=\eta_{i}\left(A-B p_{i}\right) .
$$

Here, in order to simplify the calculation, we define $1 /(1-$ $\left.\zeta_{i}\right)=\eta_{i}$ in (10). $A$ and $B$ can be determined by $\omega_{j}$, and $\xi_{j}$, described by

$$
\begin{aligned}
& A=\sum_{j \in \mathbf{J}} \frac{\eta_{i} \omega_{j}}{\xi_{j}}, \\
& B=\sum_{j \in \mathbf{J}} \frac{\eta_{i}}{\xi_{j}} .
\end{aligned}
$$


4.2. Utility Function of Retailers. Based on [44], the power supply function is defined by

$$
f_{i}(\mathbf{p})=\widehat{D}_{i}-\varepsilon_{i} p_{i}+\sum_{n=1, n \neq i}^{I} v_{i, n} p_{n}
$$

Here, the vector is denoted as $\mathbf{p}=\left[p_{1}, p_{2}, \ldots, p_{i}, \ldots, p_{I}\right]^{T}$. $\varepsilon_{i} \in[0,1]$ denotes the elastic coefficient of the price offered by retailer $i . v_{i, n} \in[0,1]$ means energy transfer ratio from retailer $i$ to retailer $n . v_{i, n}=0$ and $v_{i, n}=1$ mean that power retailer $n$ does not supply power to retailer $i$ and vice versa, respectively.

According to $[45,46]$, the retailers can adjust the amount of power supply based on the demands of users and then make the optimal pricing strategy with maximum profits. In our paper, the elastic coefficient implies the effect of the change of power demand of users on the price of the retailers in a given period.

In our paper, due to the competition among retailers, a Stackelberg game is used to model the interactions of them and determine the optimal pricing strategy based on (16) and (17). The Stackelberg game is a complete information game, and there are communication efforts for the game. Each player obtains the knowledge about the optimal strategy of other players when its strategy is decided. Thus, it can make its own optimal strategy based on the information.

Retailers sell power to users for profits after obtaining the power from the power market. Based on [47, 48], the cost function for retailer $i$ can be defined as follows:

$$
C_{i}(\mathbf{p})=\alpha_{i}+\beta_{i} f_{i}(\mathbf{p})+\delta_{i}\left(f_{i}(\mathbf{p})\right)^{2},
$$

where $\alpha_{i}$ denotes the fixed cost to generate power by retailer i. $\beta_{i}$ is the rate of the variety of the cost function curve. $\delta_{i}$ denotes the variable acceleration of the cost function curve.

Then, the profit function for retailer $i$ becomes

$$
\pi_{i}(\mathbf{p})=f_{i}(\mathbf{p}) p_{i}-C_{i}(\mathbf{p})-\gamma f_{i}(\mathbf{p}),
$$

where $\gamma$ is the coefficient of the cost to transfer power through different grids.

As the prices of retailers affect the price of each other, Stackelberg game model is developed to analyze the real-time pricing and obtain the maximal profit for each retailer. Then, we have

$$
p_{i}(t+1)=\arg \max \pi_{i}\left(p_{i}(t), \mathbf{p}_{i^{\prime}}(t+1)\right),
$$

where the vector $\mathbf{p}_{i^{\prime}}(t+1)$ denotes the price of other retailers except retailer $i$ at time $t+1$.

The solution of a multistage Stackelberg game is the subgame perfect Nash equilibrium by the back-stepping method, to obtain the maximum profit for each other. It can be obtained by the derivative of $\pi_{i}\left(p_{i}(t), \mathbf{p}_{i^{\prime}}(t+1)\right)$ as follows:

$$
\frac{\partial \pi_{i}(\mathbf{p})}{\partial p_{i}}=0
$$

Due to the dynamic feature of the power market and incomplete information, each retailer may not acquire enough information about other competitors in the game. Then retailers are not be able to make the suitable pricing strategy for the maximum profit. The modified function can be introduced as follows:

$$
p_{i}(t+1)=p_{i}(t)+\tau_{i} p_{i}(t) \frac{\partial \pi_{i}\left(p_{i}(t), \mathbf{p}_{i^{\prime}}(t)\right)}{\partial p_{i}}
$$

Here, as the retailer may adjust his current price to the optimal for obtaining the best utility, we introduce a modified parameter for the price $\tau_{i}>0$, which means the adjustment speed on the price.

Based on (17), a two-dimensional mapping related to dynamic game model is expressed as

$$
\begin{aligned}
& p_{i}(t+1)=p_{i}(t) \\
& +\tau_{i} p_{i}(t) \frac{\partial \pi_{i}\left(p_{1}(t), \ldots, p_{i-1}(t), p_{i}(t), \ldots, p_{I}(t)\right)}{\partial p_{i}} .
\end{aligned}
$$

The power retailer can get Nash equilibrium after several rounds of the game. In this case, if one of retailers in the game does not change the price, the others will not change their prices, either.

$$
\begin{gathered}
p_{1}(t+1)=p_{1}(t)=p_{1}^{*} \\
p_{2}(t+1)=p_{2}(t)=p_{2}^{*} \\
\vdots \\
p_{i-1}(t+1)=p_{i-1}(t)=p_{i-1}^{*} \\
p_{i}(t+1)=p_{i}(t)=p_{i}^{*} \\
\vdots \\
p_{I}(t+1)=p_{I}(t)=p_{I}^{*},
\end{gathered}
$$

where $p_{i}^{*}(i \in(1,2, \ldots, I))$ is the optimal price.

Then, based on (10), (12)-(14), and (17)-(19), we have

$$
\begin{aligned}
& p_{1}(t)\left\{-2\left(\eta_{1} B+\varepsilon_{1}\right)\left[1+\delta_{1}\left(\eta_{1} B+\varepsilon_{1}\right)\right] p_{1}(t)\right. \\
& \quad+\left[\nu_{1,2} p_{2}(t)+\nu_{1,3} p_{3}(t)+\cdots+\nu_{1, i} p_{i}(t)+\cdots\right. \\
& \left.\quad+\nu_{1, I} p_{I}(t)+\eta_{1} A\right]\left[1+2 \delta_{1}\left(\eta_{1} B+\varepsilon_{1}\right)\right]+\left(\eta_{1} B\right. \\
& \left.\left.\quad+\varepsilon_{1}\right)\left(\beta_{1}+\gamma\right)\right\}=0 \\
& p_{2}(t)\left\{-2\left(\eta_{2} B+\varepsilon_{2}\right)\left[1+\delta_{2}\left(\eta_{2} B+\varepsilon_{2}\right)\right] p_{2}(t)\right.
\end{aligned}
$$




$$
\begin{aligned}
& +\left[\nu_{2,1} p_{1}(t)+\nu_{2,3} p_{3}(t)+\cdots+\nu_{2, i} p_{i}(t)+\cdots\right. \\
& \left.+\nu_{2, I} p_{I}(t)+\eta_{2} A\right]\left[1+2 \delta_{2}\left(\eta_{2} B+\varepsilon_{2}\right)\right]+\left(\eta_{2} B\right. \\
& \left.\left.+\varepsilon_{2}\right)\left(\beta_{2}+\gamma\right)\right\}=0 \\
& p_{i}(t)\left\{-2\left(\eta_{i} B+\varepsilon_{i}\right)\left[1+\delta_{i}\left(\eta_{i} B+\varepsilon_{i}\right)\right] p_{i}(t)\right. \\
& +\left[\sum_{n=1, n \neq i}^{I} v_{i, n} p_{n}(t)+\eta_{i} A\right] \times\left[1+2 \delta_{i}\left(\eta_{i} B+\varepsilon_{i}\right)\right] \\
& \left.+\left(\eta_{i} B+\varepsilon_{i}\right)\left(\beta_{i}+\gamma\right)\right\}=0 \\
& p_{I}(t)\left\{-2\left(\eta_{I} B+\varepsilon_{I}\right)\left[1+\delta_{I}\left(\eta_{I} B+\varepsilon_{I}\right)\right] p_{I}(t)\right. \\
& +\left[\sum_{n=1, n \neq I}^{I} v_{I, n} p_{n}(t)+\eta_{I} A\right] \times\left[1+2 \delta_{I}\left(\eta_{I} B+\varepsilon_{I}\right)\right] \\
& \left.+\left(\eta_{I} B+\varepsilon_{I}\right)\left(\beta_{I}+\gamma\right)\right\}=0
\end{aligned}
$$

The fixed points in (18) are

$$
M_{0}:\left\{\begin{array}{l}
p_{1}=0 \\
p_{2}=0 \\
\vdots \\
p_{I-1}=0 \\
p_{I}=0,
\end{array}\right.
$$

$M_{i}$ :

$$
\left\{\begin{array}{l}
p_{1}=0 \\
p_{2}=0 \\
\vdots \\
p_{i-1}=0 \\
p_{i}=\frac{\eta_{i} A\left[1+2 \delta_{i}\left(\eta_{i} B+\varepsilon_{i}\right)\right]+\left(\eta_{i} B+\varepsilon_{i}\right)\left(\beta_{i}+\gamma\right)}{2\left(\eta_{i} B+\varepsilon_{i}\right)\left[1+\delta_{i}\left(\eta_{i} B+\varepsilon_{i}\right)\right]} \\
\vdots \\
p_{I-1}=0 \\
p_{I}=0 .
\end{array}\right.
$$

Substituting (16)-(19) into (20), it can also be rewritten by

$$
L \mathbf{p}^{*}=H
$$

where $L$ and $H$ are shown in the following:

$$
\begin{aligned}
& L=\left[\begin{array}{cccc}
-2\left(\eta_{1} B+\varepsilon_{1}\right)\left[1+\delta_{1}\left(\eta_{1} B+\varepsilon_{1}\right)\right] & {\left[1+2 \delta_{1}\left(\eta_{1} B+\varepsilon_{1}\right)\right] \nu_{1,2}} & \ldots & {\left[1+2 \delta_{1}\left(\eta_{1} B+\varepsilon_{1}\right)\right] \nu_{1, I}} \\
{\left[1+2 \delta_{2}\left(\eta_{2} B+\varepsilon_{2}\right)\right] \nu_{2,1}} & -2\left(\eta_{2} B+\varepsilon_{2}\right)\left[1+\delta_{2}\left(\eta_{2} B+\varepsilon_{2}\right)\right] & \ldots & {\left[1+2 \delta_{2}\left(\eta_{2} B+\varepsilon_{2}\right)\right] v_{2, I}} \\
\vdots & \vdots & \vdots & \vdots \\
{\left[1+2 \delta_{I}\left(\eta_{I} B+\varepsilon_{I}\right)\right] \nu_{I, 1}} & {\left[1+2 \delta_{I}\left(\eta_{I} B+\varepsilon_{I}\right)\right] \nu_{I, 2}} & \ldots & -2\left(\eta_{I} B+\varepsilon_{I}\right)\left[1+\delta_{I}\left(\eta_{I} B+\varepsilon_{I}\right)\right]
\end{array}\right], \\
& H=\left[\begin{array}{c}
-\eta_{1} A\left[1+2 \delta_{1}\left(\eta_{1} B+\varepsilon_{1}\right)\right]-\left(\eta_{1} B+\varepsilon_{1}\right)\left(\beta_{1}+\gamma\right) \\
-\eta_{2} A\left[1+2 \delta_{2}\left(\eta_{2} B+\varepsilon_{2}\right)\right]-\left(\eta_{2} B+\varepsilon_{2}\right)\left(\beta_{2}+\gamma\right) \\
\vdots \\
-\eta_{I} A\left[1+2 \delta_{I}\left(\eta_{I} B+\varepsilon_{I}\right)\right]-\left(\eta_{I} B+\varepsilon_{I}\right)\left(\beta_{I}+\gamma\right)
\end{array}\right]
\end{aligned}
$$

Then, $\mathbf{p}^{*}$ is able to be solved when parameters are available in (20). To simplify the calculation, we study the scenario that two retailers supply power to users $(i=1,2)$. Therefore, with (23) and (25), we obtain the Stackelberg equilibrium by

$$
M^{\prime}:\left\{\begin{array}{l}
p_{1}^{*}=\frac{\Phi_{11}}{\Psi} \\
p_{2}^{*}=\frac{\Phi_{21}}{\Psi},
\end{array}\right.
$$

where

$$
\begin{aligned}
\Phi_{11} & =2\left(\eta_{2} B+\varepsilon_{2}\right)\left[1+\delta_{2}\left(\eta_{2} B+\varepsilon_{2}\right)\right] \\
\cdot & {\left[\left(\eta_{1} B+\varepsilon_{1}\right)\left(2 \delta_{1} \eta_{1} A+\beta_{1}+\gamma\right)+\eta_{1} A\right]+v_{1,2} } \\
\times & {\left[1+2 \delta_{1}\left(\eta_{1} B+\varepsilon_{1}\right)\right] } \\
\cdot & {\left[\left(\eta_{2} B+\varepsilon_{2}\right)\left(2 \delta_{2} \eta_{2} A+\beta_{2}+\gamma\right)+\eta_{2} A\right] } \\
\Phi_{21} & =2\left(\eta_{1} B+\varepsilon_{1}\right)\left[1+\delta_{1}\left(\eta_{1} B+\varepsilon_{1}\right)\right]
\end{aligned}
$$




$$
\begin{aligned}
\cdot & {\left[\left(\eta_{2} B+\varepsilon_{2}\right)\left(2 \delta_{2} \eta_{2} A+\beta_{2}+\gamma\right)+\eta_{2} A\right]+v_{2,1} } \\
\times & {\left[1+2 \delta_{2}\left(\eta_{2} B+\varepsilon_{2}\right)\right] } \\
\cdot & {\left[\left(\eta_{1} B+\varepsilon_{1}\right)\left(2 \delta_{1} \eta_{1} A+\beta_{1}+\gamma\right)+\eta_{1} A\right], } \\
\Psi= & 4\left(\eta_{1} B+\varepsilon_{1}\right)\left(\eta_{2} B+\varepsilon_{2}\right)\left[1+\delta_{1}\left(\eta_{1} B+\varepsilon_{1}\right)\right] \\
& \times\left[1+\delta_{2}\left(\eta_{2} B+\varepsilon_{2}\right)\right] \\
& -v_{1,2} v_{2,1}\left[1+2 \delta_{1}\left(\eta_{1} B+\varepsilon_{1}\right)\right]\left[1+2 \delta_{2}\left(\eta_{2} B+\varepsilon_{2}\right)\right] .
\end{aligned}
$$

Remark 1. Due to the better feature of smart grid in transferring power, the cost in transferring power is lower. And, there are lots of users supplied by retailers. Thus, in (24), the constraints should satisfy $\gamma<2 \delta_{I}\left(\eta_{I} A-2\right)-\beta_{I}$.

And in order to satisfy that $\Psi$ is greater than or equal to 0 , the positive parameters in (26) are satisfied as

$$
\begin{gathered}
\frac{2\left(\eta_{1} B+\varepsilon_{1}\right)\left(\eta_{2} B+\varepsilon_{2}\right)}{\left[1+\delta_{1}\left(\eta_{1} B+\varepsilon_{1}\right)+\delta_{2}\left(\eta_{2} B+\varepsilon_{2}\right)\right]^{2}} \\
>\frac{v_{1,2} v_{2,1}}{\left(1+\delta_{1} \varepsilon_{1}\right)\left(1+\delta_{2} \varepsilon_{2}\right)} .
\end{gathered}
$$

\section{Analysis of the Stability}

In order to study the stability of the dynamic pricing strategy related to profits of retailers, we design a Jacobian matrix based on the model of two-dimensional mapping (18) for two retailers $(i=1,2)$.

$$
\mathbf{F}\left(p_{1}, p_{2}\right)=\left[\begin{array}{cc}
1+\Gamma_{11} & \Gamma_{12} \\
\Gamma_{21} & 1+\Gamma_{22}
\end{array}\right]
$$

where

$$
\begin{aligned}
\Gamma_{11} & =\tau_{1}\left\{v_{1,2}\left[1+2 \delta_{1}\left(\eta_{1} B+\varepsilon_{1}\right)\right] p_{2}\right. \\
& \left.+\left(2 \delta_{1} \eta_{1} A+\beta_{1}+\gamma\right)\left(\eta_{1} B+\varepsilon_{1}\right)+\eta_{1} A\right\}-4 \tau_{1}\left(\eta_{1} B\right. \\
& \left.+\varepsilon_{1}\right)\left[1+\delta_{1}\left(\eta_{1} B+\varepsilon_{1}\right)\right] p_{1}, \\
\Gamma_{22} & =\tau_{2}\left\{v_{2,1}\left[1+2 \delta_{2}\left(\eta_{2} B+\varepsilon_{2}\right)\right] p_{1}\right. \\
& \left.+\left(2 \delta_{2} \eta_{2} A+\beta_{2}+\gamma\right)\left(\eta_{2} B+\varepsilon_{2}\right)+\eta_{2} A\right\}-4 \tau_{2}\left(\eta_{2} B\right. \\
& \left.+\varepsilon_{2}\right)\left[1+\delta_{2}\left(\eta_{2} B+\varepsilon_{2}\right)\right] p_{2}, \\
\Gamma_{12} & =\tau_{1} \nu_{1,2}\left[1+2 \delta_{1}\left(\eta_{1} B+\varepsilon_{1}\right)\right] p_{1}, \\
\Gamma_{21} & =\tau_{2} \nu_{2,1}\left[1+2 \delta_{2}\left(\eta_{2} B+\varepsilon_{2}\right)\right] p_{2} .
\end{aligned}
$$

We investigate and prove the stability of the Stackelberg equilibrium as follows.

Theorem 2. The pricing system shown in (18) is unstable at the points $M_{0}, M_{1}$, and $M_{2}$, respectively.
Proof. First of all, substituting $M_{0}$ into (29), we have

$$
\mathbf{F}\left(M_{0}\right)=\left[\begin{array}{cc}
1+\Gamma_{11}\left(M_{0}\right) & 0 \\
0 & 1+\Gamma_{22}\left(M_{0}\right)
\end{array}\right]
$$

where

$$
\begin{aligned}
& \Gamma_{11}\left(M_{0}\right)=\tau_{1}\left[\left(2 \delta_{1} \eta_{1} A+\beta_{1}+\gamma\right)\left(\eta_{1} B+\varepsilon_{1}\right)+\eta_{1} A\right], \\
& \Gamma_{22}\left(M_{0}\right)=\tau_{2}\left[\left(2 \delta_{2} \eta_{2} A+\beta_{2}+\gamma\right)\left(\eta_{2} B+\varepsilon_{2}\right)+\eta_{2} A\right] .
\end{aligned}
$$

Based on the proposed pricing strategy with the Lyapunov Stability Theory, we analyze the stability of (18).

$$
\begin{aligned}
Q\left(M_{0}\right) & =-\mathbf{F}\left(M_{0}\right)^{T}-\mathbf{F}\left(M_{0}\right) \\
& =\left[\begin{array}{cc}
-2-2 \Gamma_{11}\left(M_{0}\right) & 0 \\
0 & -2-2 \Gamma_{22}\left(M_{0}\right)
\end{array}\right] .
\end{aligned}
$$

According to Remark 1 , we can obtain $-2-2 \Gamma_{11}\left(M_{0}\right)<0$ and prove that it is unstable at point $M_{0}$.

Based on (18)-(19) and (22), with the similar method, we can obtain $-1-\Gamma_{11}\left(M_{1}\right)<0$. Thus, we prove that it is unstable at point $M_{1}$. With the same method, we can also prove that it is unstable at point $M_{2}$. Therefore, we prove Theorem 2 .

Theorem 3. The pricing system shown in (18) is asymptotically stable at point $M^{\prime}$.

Proof. Firstly, substituting $M^{\prime}$ into (29), the Jacobian matrix is rewritten by

$$
\mathbf{F}\left(M^{\prime}\right)=\left[\begin{array}{cc}
1-\Gamma_{11}\left(M^{\prime}\right) p_{1}^{*} & \Gamma_{12}\left(M^{\prime}\right) p_{1}^{*} \\
\Gamma_{21}\left(M^{\prime}\right) p_{2}^{*} & 1-\Gamma_{22}\left(M^{\prime}\right) p_{2}^{*}
\end{array}\right]
$$

where

$$
\begin{aligned}
& \Gamma_{11}\left(M^{\prime}\right)=2 \tau_{1}\left(\eta_{1} B+\varepsilon_{1}\right)\left[1+\delta_{1}\left(\eta_{1} B+\varepsilon_{1}\right)\right], \\
& \Gamma_{12}\left(M^{\prime}\right)=\tau_{1} v_{1,2}\left[1+2 \delta_{1}\left(\eta_{1} B+\varepsilon_{1}\right)\right], \\
& \Gamma_{21}\left(M^{\prime}\right)=\tau_{2} v_{2,1}\left[1+2 \delta_{2}\left(\eta_{2} B+\varepsilon_{2}\right)\right], \\
& \Gamma_{22}\left(M^{\prime}\right)=2 \tau_{2}\left(\eta_{2} B+\varepsilon_{2}\right)\left[1+\delta_{2}\left(\eta_{2} B+\varepsilon_{2}\right)\right] .
\end{aligned}
$$

In order to satisfy the stability, we have

$$
\begin{aligned}
& \Gamma_{11}\left(M^{\prime}\right) p_{1}^{*}-1>0, \\
& {\left[1-\Gamma_{11}\left(M^{\prime}\right) p_{1}^{*}\right]\left[1-\Gamma_{22}\left(M^{\prime}\right) p_{2}^{*}\right]} \\
& \quad>\Gamma_{12}\left(M^{\prime}\right) \Gamma_{21}\left(M^{\prime}\right) p_{1}^{*} p_{2}^{*} .
\end{aligned}
$$

Furthermore, due to the property of implicit function in (23), we have

$$
\begin{aligned}
1- & \Gamma_{11}\left(M^{\prime}\right) p_{1}^{*}-\Gamma_{22}\left(M^{\prime}\right) p_{2}^{*} \\
& =\left[\Gamma_{12}\left(M^{\prime}\right) \Gamma_{21}\left(M^{\prime}\right)-\Gamma_{11}\left(M^{\prime}\right) \Gamma_{22}\left(M^{\prime}\right)\right] p_{1}^{*} p_{2}^{*} .
\end{aligned}
$$


TABLE 1: Simulation parameters.

\begin{tabular}{lc}
\hline Items & Value/assumptions \\
\hline $\begin{array}{l}\text { The signal noise power in direct } \\
\text { communication and cooperative } \\
\text { communication, respectively }\end{array}$ & $-40 \mathrm{dBm}$ \\
$\begin{array}{l}\text { Path loss exponent } \kappa \\
\text { The threshold value of SNR } \gamma_{\text {th }}\end{array}$ & 3 \\
$\begin{array}{l}\text { The antenna gain constant } K_{i}(i=1,2) \\
\text { Transmission power in direct } \\
\text { communication }\end{array}$ & $5 \mathrm{dBm}$ \\
$\begin{array}{l}\text { Transmission power in cooperative } \\
\text { communication }\end{array}$ & $0.2 \mathrm{~W}$ \\
$\begin{array}{l}\text { Covering distance in the wireless } \\
\text { communication }\end{array}$ & $0.1 \mathrm{~W}$ \\
\hline
\end{tabular}

Through solving (37), we can get the region where the pricing system (18) is asymptotically stable. At the same time, the points which intersect with the horizontal axis and vertical axis are shown as follows:

$$
\begin{aligned}
& \mathscr{A}:\left\{\begin{array}{l}
\tau_{1}=0 \\
\tau_{2}=\frac{\Psi}{2 \Phi_{21}\left(\eta_{2} B+\varepsilon_{2}\right)\left[1+\delta_{2}\left(\eta_{2} B+\varepsilon_{2}\right)\right]},
\end{array}\right. \\
& \mathscr{B}:\left\{\begin{array}{l}
\tau_{1}=\frac{\Psi}{2 \Phi_{12}\left(\eta_{1} B+\varepsilon_{1}\right)\left[1+\delta_{1}\left(\eta_{1} B+\varepsilon_{1}\right)\right]} \\
\tau_{2}=0 .
\end{array}\right.
\end{aligned}
$$

\section{Simulation Results}

Simulation experiments are used to verify the performance of the proposal. We assume that there are two retailers in the power market. Retailer 1 is the small-scaled power retailer while retailer 2 is the large-scaled one. Based on [22], the parameters of the utility function for power users are set by $A=2$ and $B=0.1$. At the same time, according to the scenario in [32], we determine the related parameters as follows: $\varepsilon_{1}=0.5, \varepsilon_{2}=0.6, \alpha_{1}=0.5, \alpha_{2}=2, \beta_{1}=0.5$, $\beta_{2}=0.2, \delta_{1}=\delta_{2}=0.5$, and $\gamma=0.5$. Here, based on different power supply capacity of these two retailers, we define $v_{2,1}=\omega v_{1,2}$ and $\sigma_{\theta}^{2}=1$. We assume that the noise in this paper is additive white Gaussian noise (AWGN), and its variance is $\sigma^{2}=-40 \mathrm{dBm}$. Based on $[43,49]$, we determine other parameters and summarize them in Table 1.

We first show the relationship between the energy transfer ratio and the price by Figure 2 . We can know that both of prices of two retailers keep increasing with the increase of the energy transfer ratio. And the difference between the two retailers becomes less and less with the increase of energy transfer ratio, although the price offered by retailer 2 is lower than that of retailer 1 initially.

We continue to evaluate the relationship between the profits of retailers and the energy transfer ratio in Figure 3. Both of the profits keep increasing with the increase of energy transfer ratio. Based on Figures 2 and 3, it is implied that

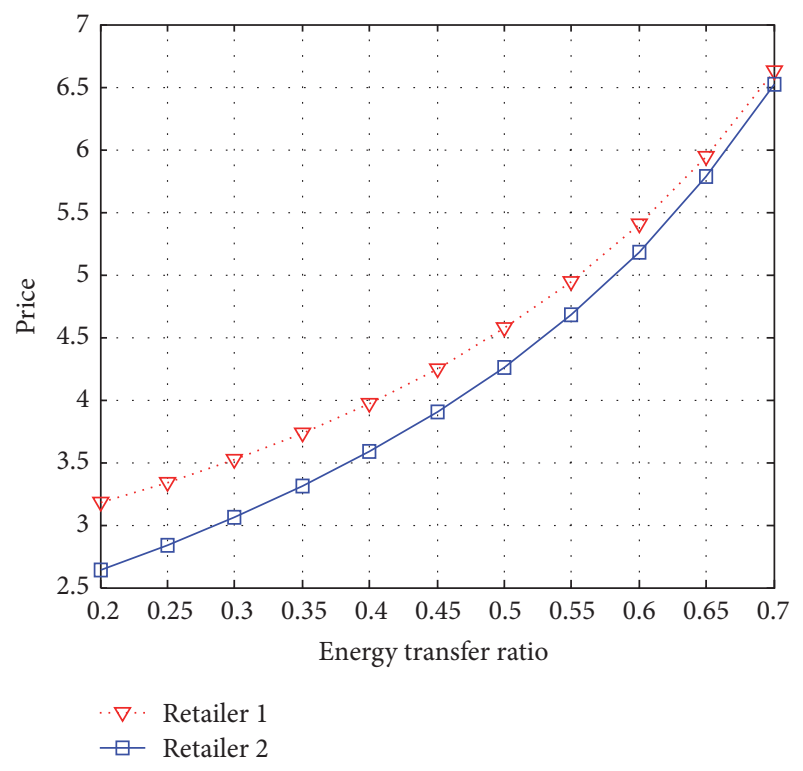

FIGURE 2: Relationship between the energy transfer ratio and the price with $\omega=1.2$.

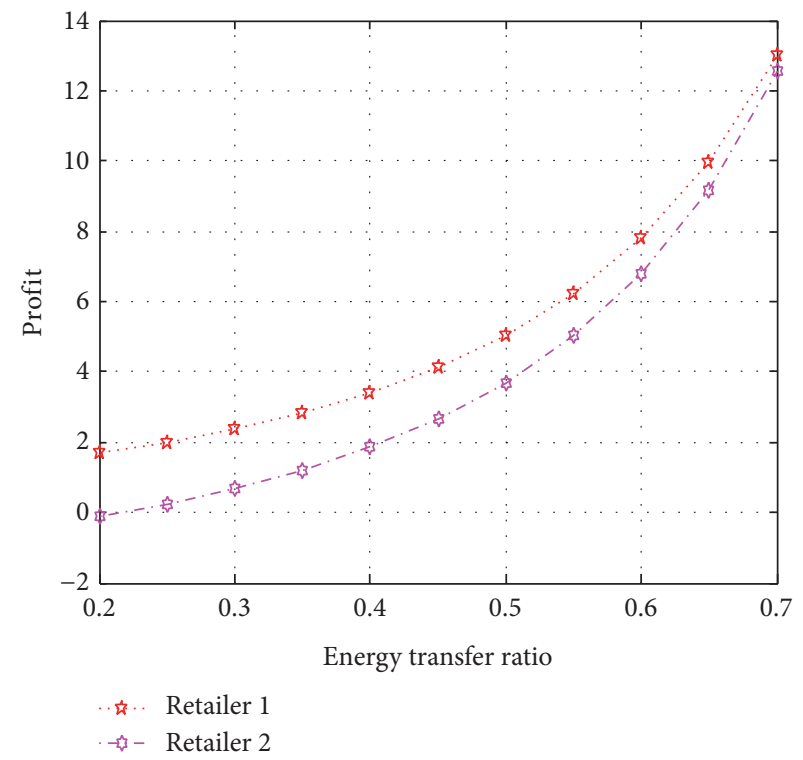

FIGURE 3: Relationship between the energy transfer ratio and the profit with $\omega=1.2$.

retailers can obtain more profits through a higher energy transfer ratio.

Next, in order to study the pricing strategy, we investigate the impact of the outage on the optimal price and profit, respectively. Based on the results in Figures 2 and 3, we set $v_{1,2}$ to be 0.2 . In Figure 4, we can see how the outage of retailer 1 affects its optimal price as well as its profits, where they keep increasing with increase of its outage. In Figure 5, the optimal price and profits of retailer 2 also keep increasing with increase of its outage.

In addition, we test the stability of the price when the modified parameters for the prices $\tau_{1}$ and $\tau_{2}$ are changed. 


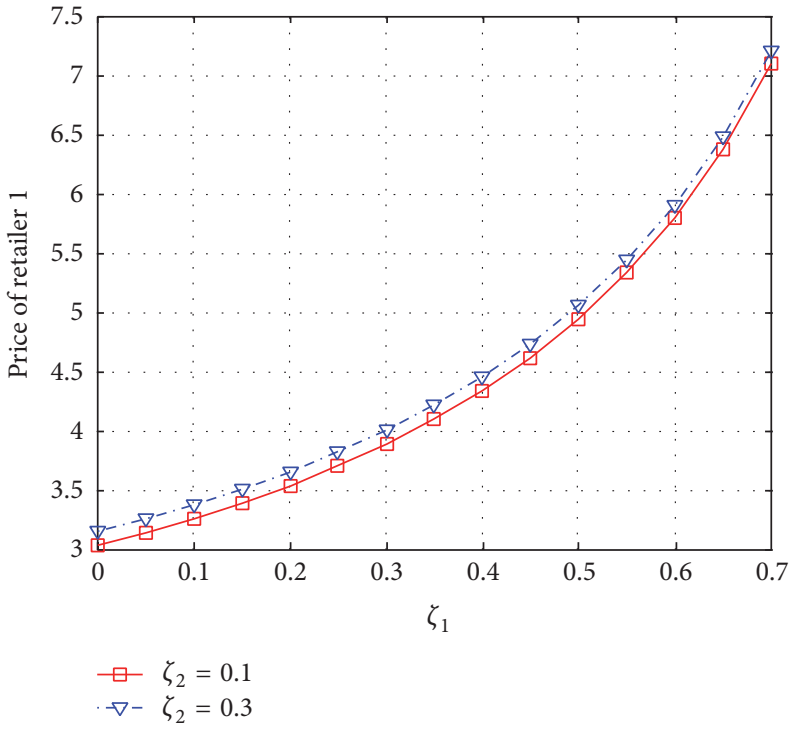

(a)

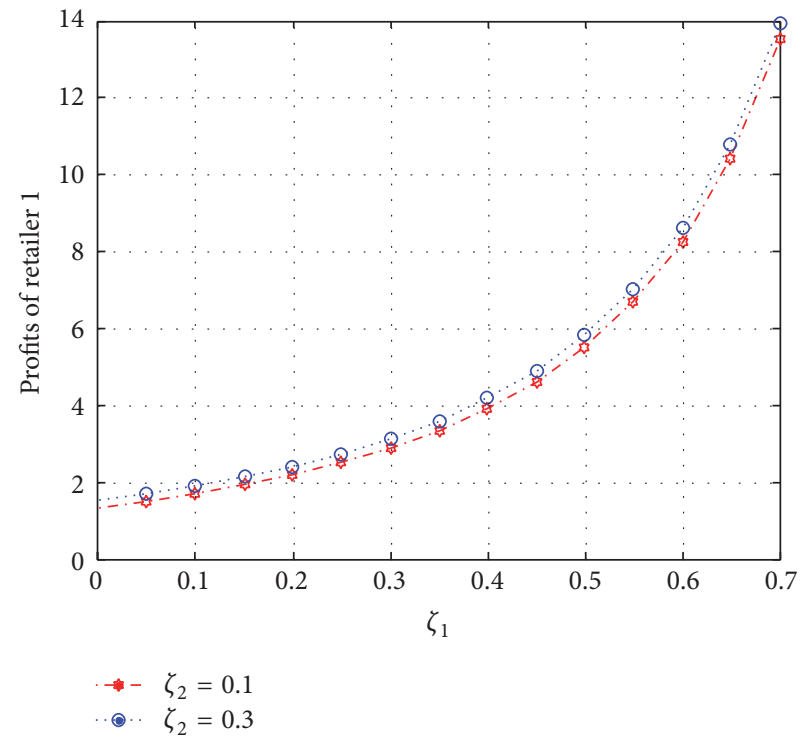

(b)

FIgURE 4: (a) The outage versus the price for retailer 1. (b) The outage versus the profit for retailer 1.

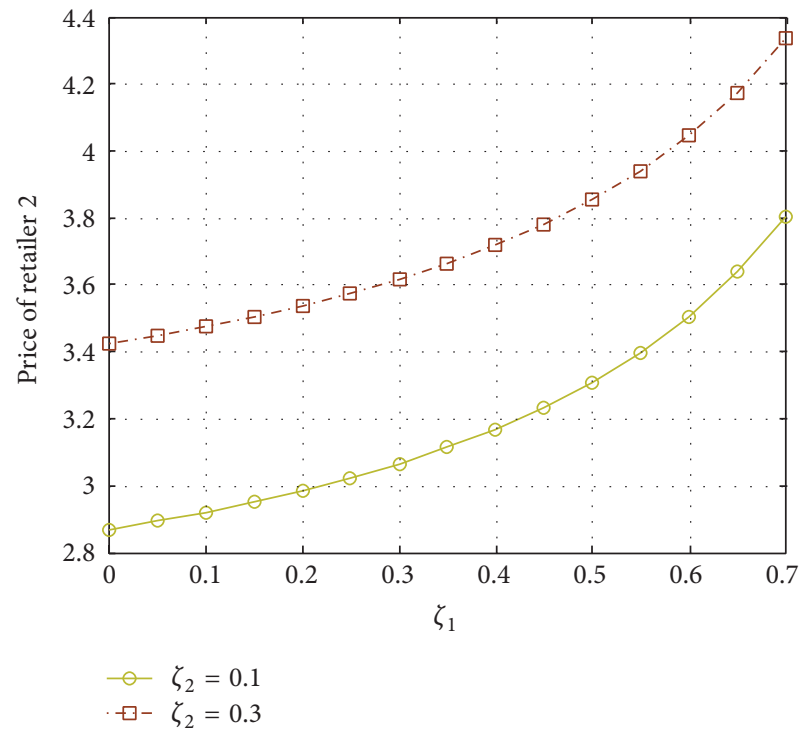

(a)

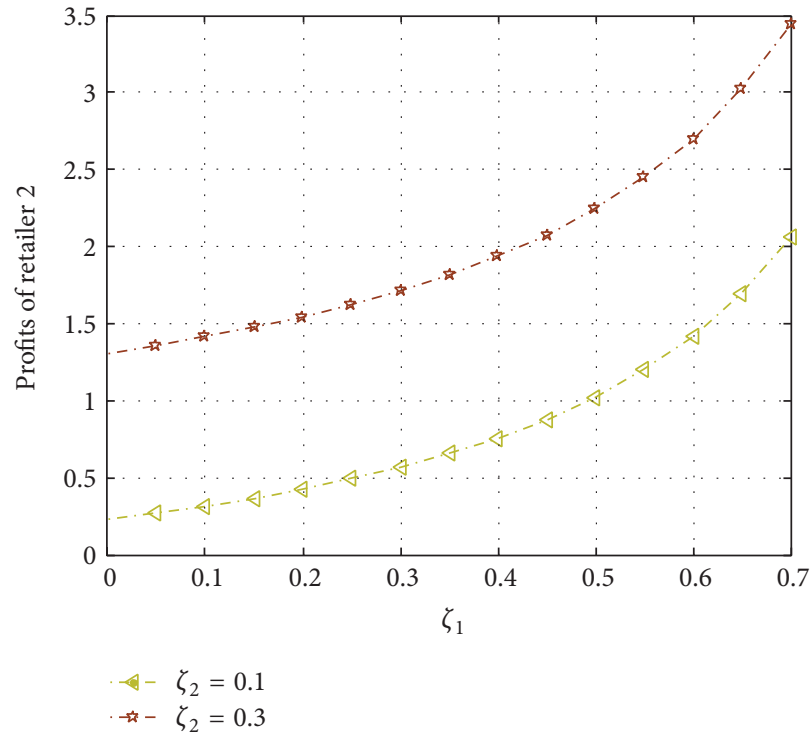

(b)

FIgUre 5: (a) The outage versus the price for retailer 2. (b) The outage versus the profit for retailer 2.

Here, the energy transfer ratios of retailer 1 and retailer 2 are 0.3 and 0.36 , respectively. In Figure 6, we can obtain the stable region when both the modified parameters and outage are changed.

In Figure 7, we study the system stability related to the optimal pricing strategy among different power retailers. When the value of iteration is changed, both of the prices of retailer 1 and retailer 2 keep increasing and then become stable. From the results, we can know that the optimal price of these power retailers can be stable when the related parameters are changed.

Finally, we compare performance of the proposed scheme with the existing scheme [50]. Here, we consider the overhead function of price adjustment as $\varphi_{i}=\varrho_{i}\left(p_{i}(t+\Delta t)-p_{i}(t)\right)^{2}+\epsilon_{i}$ $\left(\Delta t=\mathbb{N}^{+}\right)$, which is also used to evaluate the proposed scheme and existing scheme, respectively. In this function, $\varrho_{i}$ and $\epsilon_{i}$ denote the preset parameters where $\zeta_{1}=0.1$ and $\zeta_{2}=0.5$. Figure 8 depicts the overhead when the speed of price adjustment is changed when $\varrho_{1}=\varrho_{2}=5, \epsilon_{1}=\epsilon_{2}=3$. It can be known that the overhead with the existing scheme is larger than that of the proposed scheme, which also implies that the proposed strategy is better than the existing one.

Based on the above analysis, we can know that the proposal can obtain a stable performance when the related parameters are changed. Besides, it outperforms the existing scheme with a low overhead. 


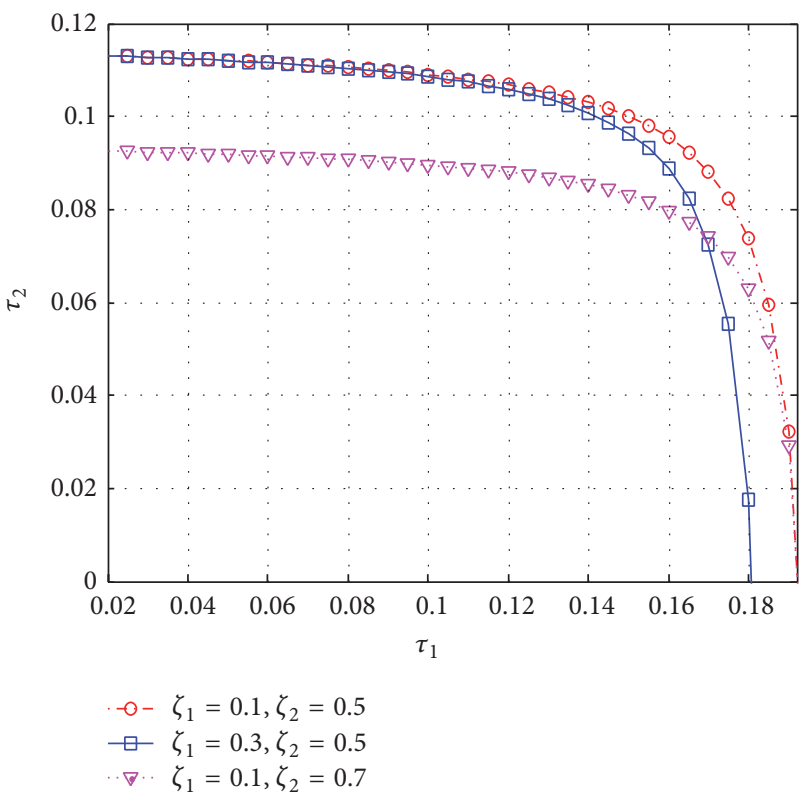

FIGURE 6: Relationship between $\tau_{1}$ and $\tau_{2}$ with different outage.

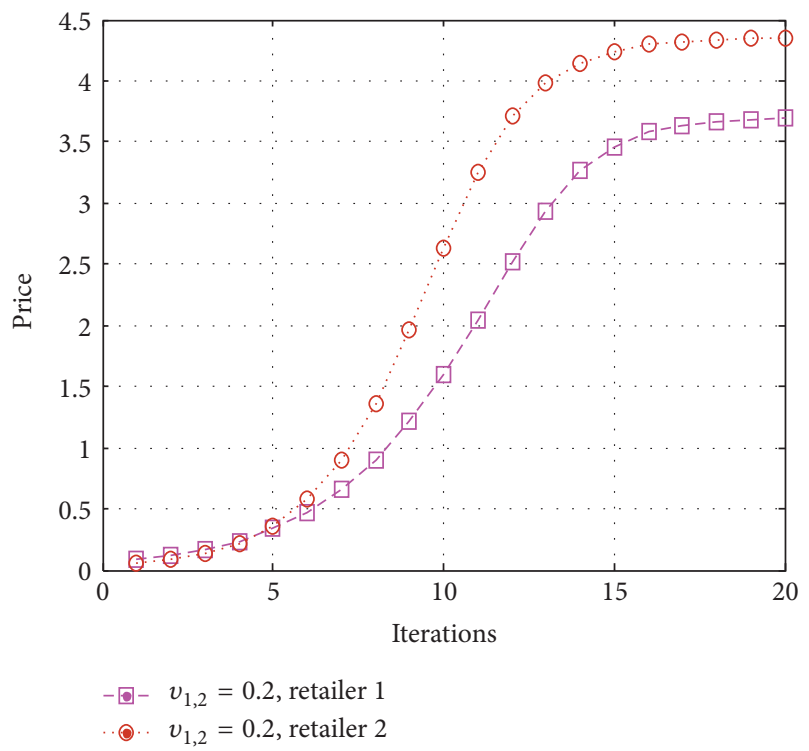

FIGURE 7: Energy transfer ratio versus optimal price.

\section{Conclusions}

This paper has presented a real-time pricing strategy with multiretailers in smart grid for green IoTs. We have analyzed the outage related to the location of relay nodes in smart grid enabled green IoTs, which affects imbalance between power supply and demand. Then, a Stackelberg game model has been designed to show the relationship between the profit of multiretailers and the pricing. Next, the stability of the pricing has been studied under the load constraints. Finally, simulation results have shown that the proposal can outperform the other existing methods. About the future

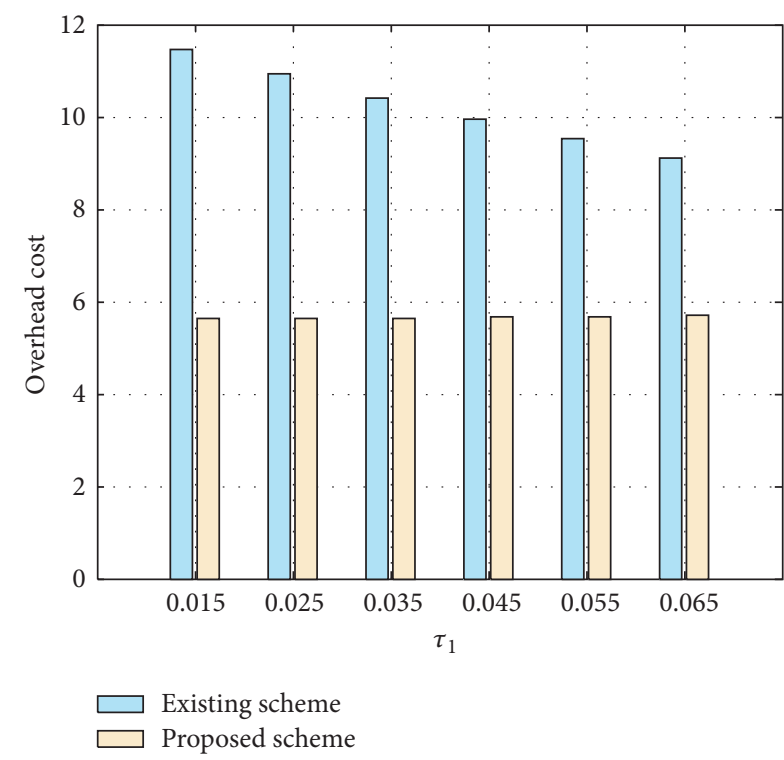

Figure 8: The overhead comparison with different schemes.

work, the model will be extended to the microgrid system including energy storage and renewable generation.

\section{Abbreviations}

J: $\quad$ Set of users in small cell, $\{1,2, \ldots, J\}$

$d_{j}$ : Power consumption of user $j$

$p_{i}$ : Power price offered by retailer $i$

p: Set of power price offered by retailers

$\gamma_{i, j}:$ The signal noise to ratio (SNR), when retailer $i$ directly communicates with user $j$

$\gamma_{\mathrm{th}}$ : The threshold value of SNR

$\zeta_{i}$ : Retailer $i$ probability of outage in heterogeneous networks

$v_{i, n}$ : Energy transfer ratio from retailer $i$ to retailer $n$

$\tau_{i}: \quad$ Retailer $i$ adjustment speed on the price

$\pi_{i}$ : Profit function of retailer $i$.

\section{Conflicts of Interest}

The authors declare that they have no conflicts of Interest.

\section{Acknowledgments}

This work was partially supported by Shanghai Key Laboratory of Power Station Automation Technology.

\section{References}

[1] G. Wu, P. Ren, and Q. Du, "Recall-based dynamic spectrum auction with the protection of primary users," IEEE Journal on Selected Areas in Communications, vol. 30, no. 10, pp. 2070-2081, 2012. 
[2] T. Han and N. Ansari, "Powering mobile networks with green energy," IEEE Wireless Communications, vol. 21, no. 1, pp. 90-96, 2014.

[3] Q. Xu, Z. Su, and S. Guo, "A game theoretical incentive scheme for relay selection services in mobile social networks," IEEE Transactions on Vehicular Technology, vol. 65, no. 8, pp. 66926702, 2016.

[4] Z. Su, Q. Xu, and Q. Qi, "Big data in mobile social networks: a QoE-oriented framework," IEEE Network, vol. 30, no. 1, pp. 5257, 2016.

[5] Y. Guo, M. Pan, Y. Fang, and P. P. Khargonekar, "Decentralized coordination of energy utilization for residential households in the smart grid," IEEE Transactions on Smart Grid, vol. 4, no. 3, pp. 1341-1350, 2013.

[6] P. Samadi, H. Mohsenian-Rad, R. Schober, and V. W. S. Wong, "Advanced demand side management for the future smart grid using mechanism design," IEEE Transactions on Smart Grid, vol. 3, no. 3, pp. 1170-1180, 2012.

[7] T. Han and N. Ansari, "On optimizing green energy utilization for cellular networks with hybrid energy supplies," IEEE Transactions on Wireless Communications, vol. 12, no. 8, pp. 38723882, 2013.

[8] Z. Su, Q. Xu, H. Zhu, and Y. Wang, "A novel design for content delivery over software defined mobile social networks," IEEE Network, vol. 29, no. 4, pp. 62-67, 2015.

[9] Y. Hui, Z. Su, and S. Guo, "Utility based data computing scheme to provide sensing service in internet of things," IEEE Transactions on Emerging Topics in Computing, pp. 1-1, 2017.

[10] Z. Su, Y. Hui, and S. Guo, "D2D-based content delivery with parked vehicles in vehicular social networks," IEEE Wireless Communications, vol. 23, no. 4, pp. 90-95, 2016.

[11] Q. Xu, P. Ren, H. Song, and Q. Du, "Security enhancement for IoT communications exposed to eavesdroppers with uncertain locations," IEEE Access, vol. 4, pp. 2840-2853, 2016.

[12] Z. Su, Y. Hui, and Q. Yang, "The next generation vehicular networks: a content-centric framework," IEEE Wireless Communications, vol. 24, no. 1, pp. 60-66, 2017.

[13] Z. Su, Q. Xu, Y. Hui, M. Wen, and S. Guo, "A game theoretic approach to parked vehicle assisted content delivery in vehicular ad hoc networks," IEEE Transactions on Vehicular Technology, 2016.

[14] V. K. Sood, D. Fischer, J. M. Eklund, and T. Brown, "Developing a communication infrastructure for the smart grid," in Proceedings of the IEEE Electrical Power and Energy Conference (EPEC '09), October 2009.

[15] X. Liu, A. Liu, Q. Deng, and H. Liu, "Large-scale programing code dissemination for software defined wireless net-works," Computer Journal, 2017.

[16] S. Bu and F. R. Yu, "Green cognitive mobile networks with small cells for multimedia communications in the smart grid environment," IEEE Transactions on Vehicular Technology, vol. 63, no. 5, pp. 2115-2126, 2014.

[17] G. A. Shah, V. C. Gungor, and O. B. Akan, "A cross-layer QoSaware communication framework in cognitive radio sensor networks for smart grid applications," IEEE Transactions on Industrial Informatics, vol. 9, no. 3, pp. 1477-1485, 2013.

[18] Z. Yin, F. R. Yu, S. Bu, and Z. Han, "Joint cloud and wireless networks operations in mobile cloud computing environments with telecom operator cloud," IEEE Transactions on Wireless Communications, vol. 14, no. 7, pp. 4020-4033, 2015.
[19] J. Wang, C. Hu, and A. Liu, "Comprehensive optimization of energy consumption and delay performance for green communication in internet of things," Mobile Information Systems, 2017.

[20] X. Liu, M. Dong, K. Ota, P. Hung, and A. Liu, "Service pricing decision in cyber-physical systems: insights from game theory," IEEE Transactions on Services Computing, vol. 9, no. 2, pp. 186198, 2016.

[21] M. Mekkanen, R. Virrankoski, M. Elmusrati, and E. Antila, "Communication system in smart grid using spectrum sensing techniques," in Proceedings of the IEEE 7th International Power Engineering and Optimization Conference (PEOCO '13), pp. 324-329, IEEE, Langkawi, Malaysia, June 2013.

[22] M. Levorato and U. Mitra, "Optimal allocation of heterogeneous smart grid traffic to heterogeneous networks," in Proceedings of the IEEE 2nd International Conference on Smart Grid Communications (SmartGridComm '11), pp. 132-137, October 2011.

[23] R. Deng, J. Chen, X. Cao, Y. Zhang, S. Maharjan, and S. Gjessing, "Sensing-performance tradeoff in cognitive radio enabled smart grid," IEEE Transactions on Smart Grid, vol. 4, no. 1, pp. 302-310, 2013.

[24] S. Bu, F. R. Yu, and Y. Qian, "Energy-efficient cognitive heterogeneous networks powered by the smart grid," in Proceedings of the 32nd IEEE Conference on Computer Communications (IEEE INFOCOM '13), pp. 980-988, Turin, Italy, April 2013.

[25] J. Huang, H. Wang, Y. Qian, and C. Wang, "Priority-based traffic scheduling and utility optimization for cognitive radio communication infrastructure-based smart grid," IEEE Transactions on Smart Grid, vol. 4, no. 1, pp. 78-86, 2013.

[26] P. Tarasak, "Optimal real-time pricing under load uncertainty based on utility maximization for smart grid," in Proceedings of the IEEE 2nd International Conference on Smart Grid Communications (SmartGridComm '11), pp. 321-326, October 2011.

[27] S. Bu, F. R. Yu, and P. X. Liu, "A game-theoretical decisionmaking scheme for electricity retailers in the smart grid with demand-side management," in Proceedings of the IEEE 2nd International Conference on Smart Grid Communications (SmartGridComm '11), pp. 387-391, Brussels, Belgium, October 2011.

[28] A. Vidal, L. Jacobs, and L. Batista, "An evolutionary approach for the demand side management optimization in smart grid," in Proceedings of the IEEE Symposium on Computational Intelligence Applications in Smart Grid (CIASG '14), pp. 1-7, Orlando, Fla, USA, December 2014.

[29] J. Ma, J. Deng, L. Song, and Z. Han, "Incentive mechanism for demand side management in smart grid using auction," IEEE Transactions on Smart Grid, vol. 5, no. 3, pp. 1379-1388, 2014.

[30] S. Ghosh and M. H. Ali, "Minimization of adverse effects of time delay in smart power grid," in Proceedings of the IEEE Power and Energy Society Innovative Smart Grid Technologies Conference (ISGT '14), February 2014.

[31] J. Matamoros, D. Gregoratti, and M. Dohler, "Microgrids energy trading in islanding mode," in Proceedings of the IEEE 3rd International Conference on Smart Grid Communications (SmartGridComm '12), pp. 49-54, IEEE, Tainan, Taiwan, November 2012.

[32] W.-Y. Chiu, H. Sun, and H. V. Poor, "Demand-side energy storage system management in smart grid," in Proceedings of the IEEE 3rd International Conference on Smart Grid Communications (SmartGridComm '12), pp. 73-78, Tainan, Taiwan, November 2012.

[33] L. Huang, J. Walrand, and K. Ramchandran, "Optimal demand response with energy storage management," in Proceedings of 
the IEEE 3rd International Conference on Smart Grid Communications (SmartGridComm '12), pp. 61-66, November 2012.

[34] A. K. Singh, R. Singh, and B. C. Pal, "Stability analysis of networked control in smart grids," IEEE Transactions on Smart Grid, vol. 6, no. 1, pp. 381-390, 2015.

[35] S. Althaher, P. Mancarella, and J. Mutale, "Automated demand response from home energy management system under dynamic pricing and power and comfort constraints," IEEE Transactions on Smart Grid, vol. 6, no. 4, pp. 1874-1883, 2015.

[36] S. Bahrami, M. Parniani, and A. Vafaeimehr, "A modified approach for residential load scheduling using smart meter," in Proceedings of the 3rd IEEE PES International Conference and Exhibition on Innovative Smart Grid Technologies (ISGT Europe '12), pp. 1379-1388, Berlin, Germany, October 2012.

[37] Z. Feng, Q. Li, W. Li, T. A. Gulliver, and P. Zhang, "Prioritybased dynamic spectrum management in a smart grid network environment," IEEE Journal on Selected Areas in Communications, vol. 33, no. 5, pp. 933-945, 2015.

[38] M. Hong and H. Zhu, "Power-efficient operation of wireless heterogeneous networks using Smart Grids," in Proceedings of the IEEE International Conference on Smart Grid Communications (SmartGridComm '14), pp. 236-241, November 2014.

[39] M. H. U. Ahmed, M. G. R. Alam, R. Kamal, C. S. Hong, and S. Lee, "Smart grid cooperative communication with smart relay," Journal of Communications and Networks, vol. 14, no. 6, pp. 640652, 2012.

[40] E. Bou-Harb, C. Fachkha, M. Pourzandi, M. Debbabi, and C. Assi, "Communication security for smart grid distribution networks," IEEE Communications Magazine, vol. 51, no. 1, pp. 4249, 2013.

[41] K. J. Ross, K. M. Hopkinson, and M. Pachter, "Using a distributed agent-based communication enabled special protection system to enhance smart grid security," IEEE Transactions on Smart Grid, vol. 4, no. 2, pp. 1216-1224, 2013.

[42] Z. Li and Q. Liang, "Downlink capacity optimization in a heterogeneous home area network with application to smart grid," in Proceedings of the IEEE Global Communications Conference (GLOBECOM '14), pp. 4677-4682, December 2014.

[43] Y. Choi and J. H. Lee, "Power allocation for cooperative jamming in amplify-and-forward relaying network with eavesdropper," in Proceedings of the 81st IEEE Vehicular Technology Conference (VTC '15), pp. 1-5, IEEE, Glasgow, Scotland, May 2015.

[44] Y. Dai and Y. Gao, "Real-time pricing strategy with multiretailers based on demand-side management for the smart grid," Proceedings of the Chinese Society of Electrical Engineering, vol. 34, no. 25, pp. 4244-4249, 2014.

[45] R. De Sá Ferreira, L. A. Barroso, P. R. Lino, M. M. Carvalho, and P. Valenzuela, "Time-of-use tariff design under uncertainty in price-elasticities of electricity demand: a stochastic optimization approach," IEEE Transactions on Smart Grid, vol. 4, no. 4, pp. 2285-2295, 2013.

[46] P. R. Thimmapuram and J. Kim, "Consumers' price elasticity of demand modeling with economic effects on electricity markets using an agent-based model," IEEE Transactions on Smart Grid, vol. 4, no. 1, pp. 390-397, 2013.

[47] P. Samadi, A. Mohsenian-Rad, R. Schober et al., "Optimal realtime pricing algorithm based on utility maximization for smart grid," in Proceedings of the IEEE International Conference on Smart Grid Communications (SmartGridComm '10), pp. 415420, October 2010.
[48] A. J. Conejo, J. M. Morales, and L. Baringo, "Real-time demand response model," IEEE Transactions on Smart Grid, vol. 1, no. 3, pp. 236-242, 2010.

[49] X. Xie, W. Lei, S. Ma et al., Cognitive and Cooperative Wireless Communication Networks, Posts \& Telecommunications Press, 2012.

[50] Y. Peng and Q. Lu, "Complex dynamics analysis for a duopoly Stackelberg game model with bounded rationality," Applied Mathematics and Computation, vol. 271, pp. 259-268, 2015. 

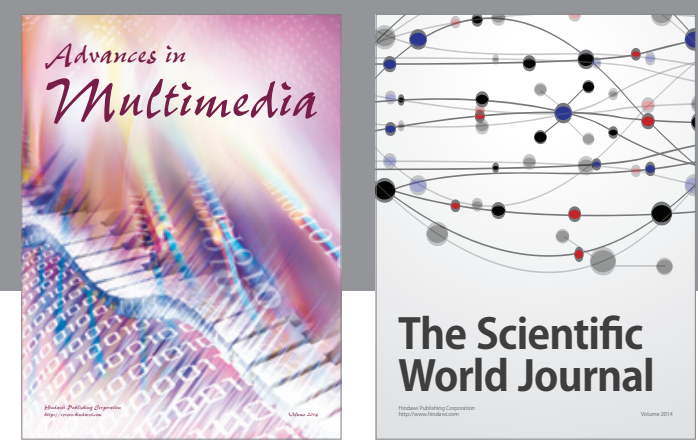

The Scientific World Journal
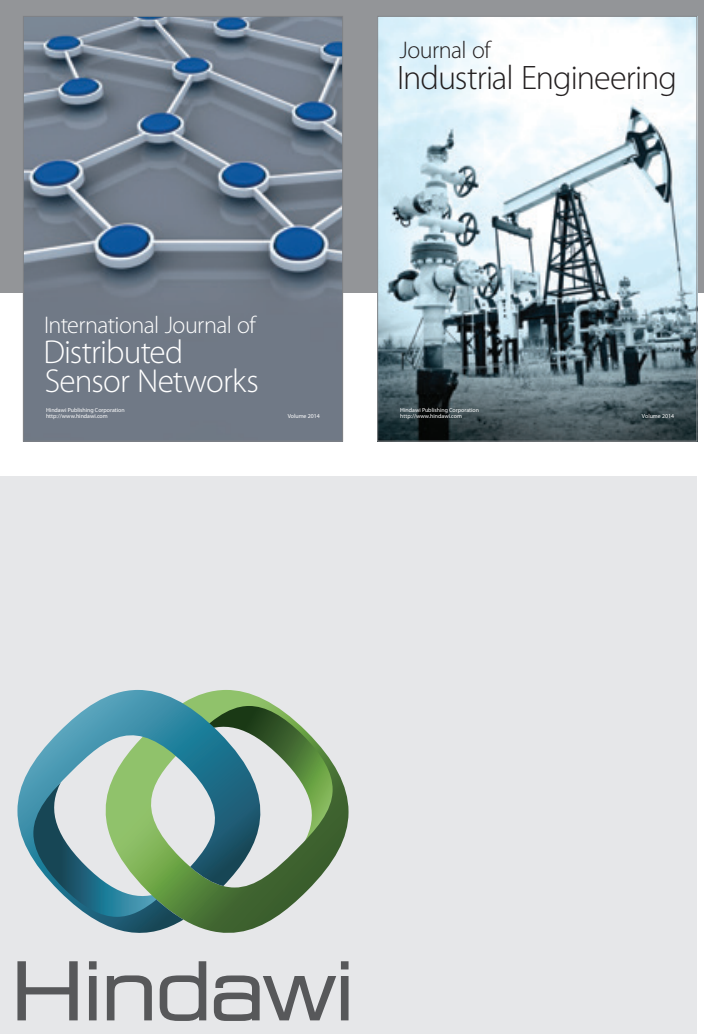

Submit your manuscripts at

https://www.hindawi.com

\section{Computer Networks} and Communications
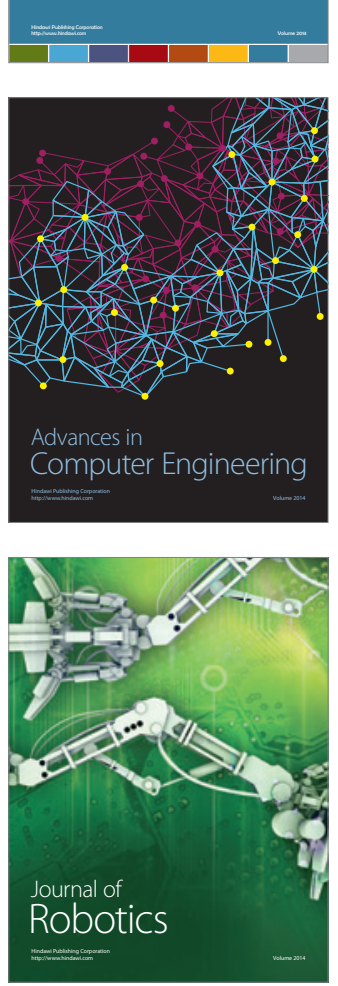
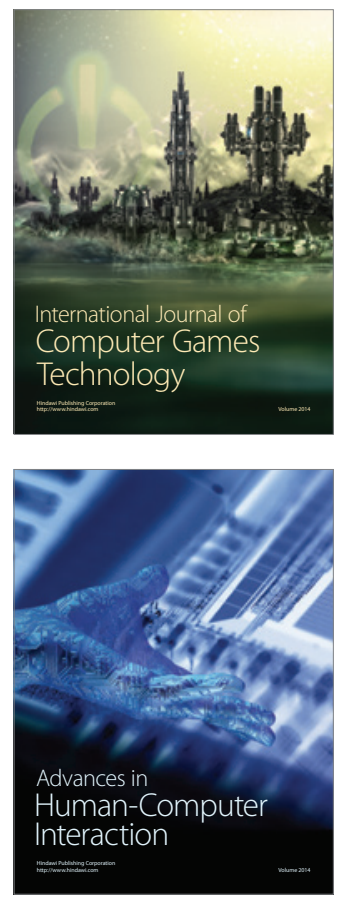
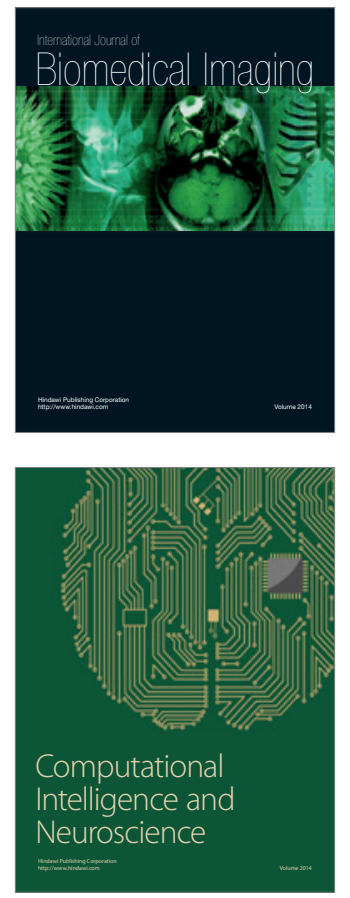
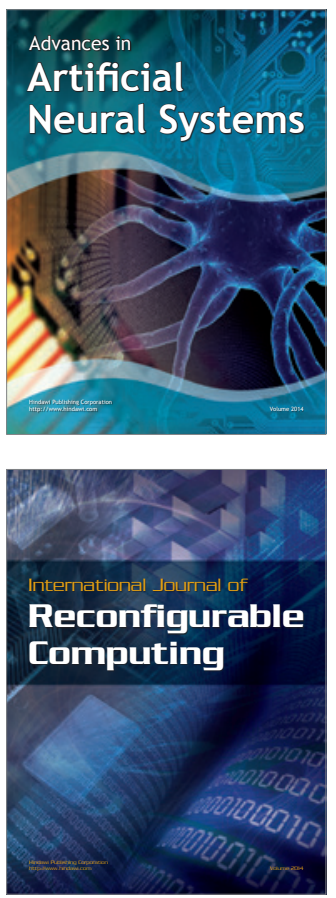
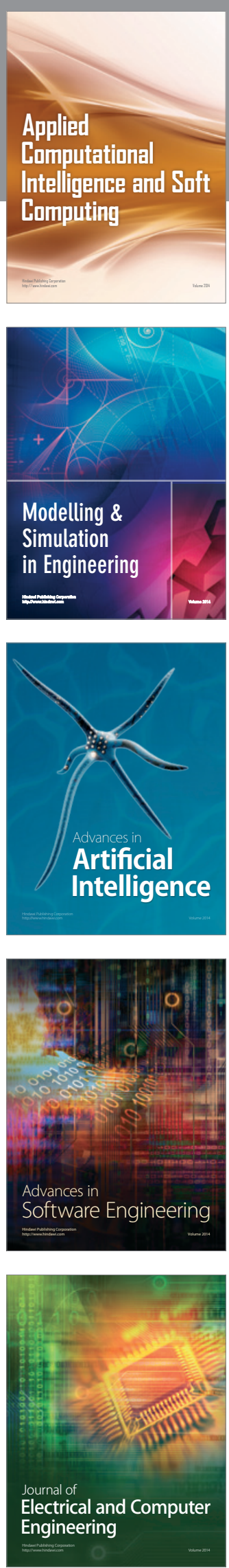